\title{
An analysis of the electrocardiogram QT interval
}

N.R. Koehler, J.P. Zouvi, L.A. Acevedo, B.J. Sukienik and M. Rabin

\author{
Serviço de Cardiologia, Departamento de Clínica Médica, \\ Faculdade de Medicina and Hospital São Lucas, \\ Pontifícia Universidade Católica, Porto Alegre, RS, Brasil
}

\section{Correspondence \\ N.R. Koehler \\ Serviço de Cardiologia \\ Departamento de Clínica Médica \\ Faculdade de Medicina, PUC \\ 90610-000 Porto Alegre, RS \\ Brasil}

Received February 27, 2003 Accepted November 27, 2003

\begin{abstract}
No reports testing the efficacy of the use of the QT/RR ratio $<1 / 2$ for detecting a normal QTc interval were found in the literature. The objective of the present study was to determine if a QT/RR ratio $\leq 1 / 2$ can be considered to be equal to the normal QTc and to compare the QT and QTc measured and calculated clinically and by a computerized electrocardiograph. Ratios (140 QT/RR) of 28 successive electrocardiograms obtained from 28 consecutive patients in a tertiary level teaching hospital were analyzed clinically by 5 independent observers and by a computerized electrocardiograph. The QT/RR ratio provided $56 \%$ sensitivity and $78 \%$ specificity, with an area under the receiver operator characteristic curve of $75.8 \%$ (95\% CI: 0.68 to 0.84 ). The divergence in QT and QTc interval measurements between clinical and computerized evaluation were $0.01 \pm 0.03 \mathrm{~s}$ (95\% CI: 0.04-0.02) and $0.01 \pm 0.04$ s (95\%CI: $-0.05-0.03)$, respectively. The QT and QTc values measured clinically and by a computerized electrocardiograph were similar. The QT/RR ratio $\leq 1 / 2$ was not a satisfactory index for QTc evaluation because it could not predict a normal QTe value.
\end{abstract}

\section{Introduction}

The ventricular electric systole, QT interval, is an important parameter because a series of physiological and pathological situations may be related to its prolongation. Examples of these conditions are vagotonia, sleeping, advanced age, myocardial ischemia, post-arrhythmia, resuscitation after heart arrest, central nervous system diseases, use of anti-arrhythmic drugs, electrolytic changes, congenital long QT syndrome, and use of psychotropic drugs (1-4). Some include predisposition to severe and even lethal ventricular arrhythmia (5). Defining higher limits for the QT interval is a difficult task, for which several tables and values are available $(6,7)$. Furthermore, superposition of normal
Key words

- Electrocardiography

- Long QT syndrome

- Arrhythmia

- QT interval and prolonged values may occur in families with congenital long QT syndrome; thus, even people with "normal" QTc may suffer severe ventricular arrhythmia $(8,9)$. Other electrocardiogram (ECG) peculiarities, such as ST-T alterations, also contribute to the identification of people affected with this syndrome (8).

In cases of left or right bundle branch block, QTc prolongation is a result of QRS increase and not of a prolongation of ventricular repolarization time (10). It should be emphasized that $2.5 \%$ of normal men and women may have QTc values exceeding 440 and $460 \mathrm{~ms}$, respectively (11).

At ECG meetings, reference is usually made to a simplified rule to determine whether QTc is normal or prolonged. According to 
this approach, if the measured QT interval is equal to or smaller than half of the corresponding R-R interval, the QTc is considered to be normal. This means that an increased QTc could be excluded without using the Bazett rule. No reports testing the efficacy of the use of the QT/RR ratio $<1 / 2$ for detecting a normal QTc interval were found in the literature. The objective of the present study was to determine if the QT/RR $\leq 1 / 2$ ratio indicates a normal QT interval and if the QT and QTc values measured by 5

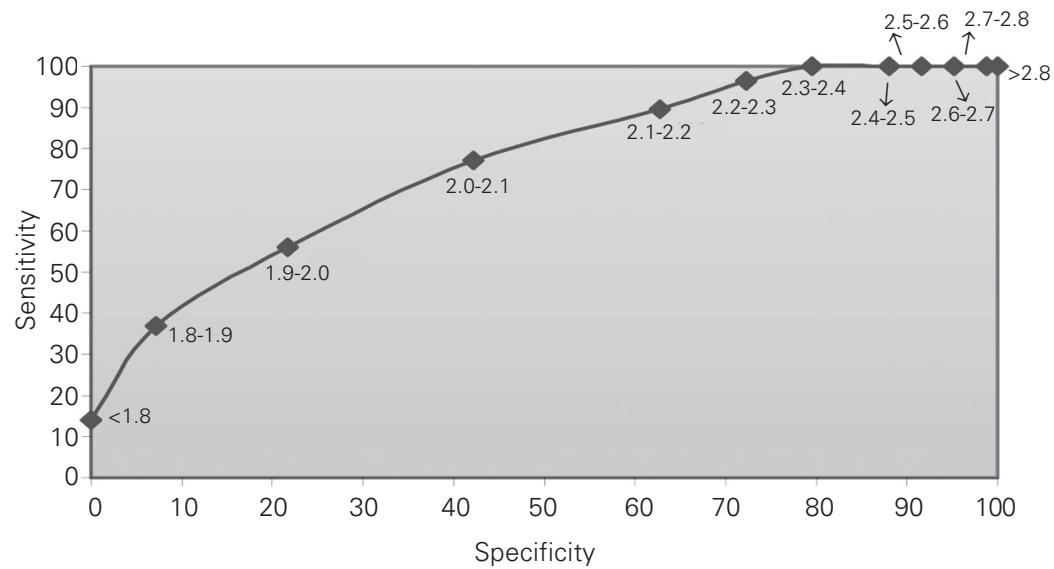

Figure 1. Receiver operator characteristic curve for the performance of the QT/RR ratio as a factor discriminating between a normal and a prolonged QTc $(>0.423 \mathrm{~s}$ for males and $>0.439 \mathrm{~s}$ for females).



Figure 2. Receiver operator characteristic curve for the performance of the QT/RR ratio as a factor identifying a prolonged Qtc ( $>0.423 \mathrm{~s}$ for males and $>0.439 \mathrm{~s}$ for females), with heart rate between 60 and $100 \mathrm{bpm}$. observers and those measured by a computerized electrocardiograph are equivalent.

\section{Material and Methods}

Twenty-eight successive ECGs obtained from 28 consecutive patients were selected for analysis in a tertiary level teaching hospital. The QT and QTc intervals of five complexes with clear limits were measured and calculated using standard rulers or a divider compass and compared with those determined with a Pagewriter 200i Hewlett-Packard (Palo Alto, CA, USA) computerized electrocardiograph software. The measurements were made from the D2 lead with the QT and the QTc measured and calculated by the Bazett formula in five successive QRS complexes; the arithmetic mean was then obtained. QTc intervals of $409 \pm 14 \mathrm{~ms}$ for adult men and $421 \pm 18$ ms for adult women were considered to be normal values according to Merri et al. (11). In addition, the same measurements were made in a separate subsample of 22 patients with sinus bradycardia.

Exclusion criteria were ECGs with heart rate (HR) below 40 and above $120 \mathrm{bpm}$, atrial fibrillation/flutter, AV or bundle branch block, ectopic beats, sinus arrhythmia, artificial pacemaker, junctional or ventricular rhythms, and ECGs from patients younger than 14 years.

\section{Statistical analysis}

Sensitivity, specificity and area under the receiver operator characteristic curve (ROC) values were determined (12) for the QT/RR $\leq 1 / 2$ ratio, taking the above measurements of QT as normal values (11). The equivalence of the observations was evaluated by the Bland and Altman (13) technique for comparison of quantitative methods.

\section{Results and Discussion}

In the whole range of HR (all records) a QT/RR ratio $\leq 1 / 2$ as evidence of normal 
QTc revealed $78 \%$ specificity and $56 \%$ sensitivity to detect normal QTc interval duration. The ROC showed an area under the curve of $75.8 \pm 4.08 \%$ (95\%CI: $0.68-0.84$ ). With an HR between 60 and $100 \mathrm{bpm}$ the ratio showed $81 \%$ specificity and $57 \%$ sensitivity, with an area under the ROC of $76.8 \pm$ 4.2\% (95\%CI: 0.69-0.85; Figures 1 and 2).

In the subgroup with HR below $60 \mathrm{bpm}$, a QT/RR ratio $\leq 1 / 2$ showed $3.1 \%$ sensitivity and $97 \%$ specificity, a zero positive predictive value and a $67 \%$ negative predictive value.

The QT and QTc differences between the average measurements made by the $5 \mathrm{ob}$ servers and by the computerized electrocardiograph in 124 tracing records were $0.01 \pm$ 0.03 s (95\%CI: $0.04-0.02)$ and $0.01 \pm 0.04 \mathrm{~s}$ (95\%CI: -0.05-0.03), respectively.

QTc is an increasingly important parameter for ECG evaluation. The practical evaluation of the QTc interval represented by a QT/RR ratio $\leq 1 / 2$ was not effective even with different cut-off points throughout the ROC. Together, sensitivity and specificity did not reach values above $75 \%$ and the area under the ROC was $75.8 \%$ in all tracing records and $76.8 \%$ in records with 60 to 100 bpm. Tracing records with HR below 60 bpm fared even worse, with sensitivity, specificity and the area under the ROC showing inadequate values.

The QTc values measured by the observers and by the electrocardiograph used in the study showed minimal negative differences of 2 to $4 \%$. We do not deem such differences to be of sufficient clinical relevance to transform a normal interval into an abnormal one.

At present, in clinical practice the QTc interval must be calculated by Bazzet's rule. A QT/RR ratio $\leq 1 / 2$ did not show a satisfactory performance as an index of normal QTc.

The QT and QTc values measured clinically and by the computerized electrocardiograph were similar.

\section{Acknowledgments}

We wish to thank Prof. Mário Wagner for statistical assistance and orientation, and the Cardiology Service, in the person of Dr. Luiz C. Bodanese, for support.

\section{References}

1. Molnar J, Zhang F, Weiss J, Ehlert FA \& Rosenthal JE (1996). Diurnal pattern of OTc interval: how long is prolonged? Possible relation to circadian triggers of cardiovascular events. Journal of the American College of Cardiology, 27: 76-83.

2. Bednar MM, Harrigan EP, Anziano RJ, Camm AJ \& Ruskin JN (2001). The QT interval. Progress in Cardiovascular Diseases, 43 (Suppl 1): 1-45.

3. Schwartz PJ, Moss AJ, Vincent GM \& Crampton RS (1993). Diagnostic criteria for the long QT syndrome. An update. Circulation, 88: 782-784.

4. Harding JD, Piacentino 3rd V, Gaughan JP, Houser SR \& Margulies KB (2001). Electrophysiological alterations after mechanical circulatory support in patients with advanced cardiac failure. Circulation, 104: 1241-1247.

5. Ramos MGD, Belloti KC, Zeni MC, Pimentel Filho P \& Rey N (1998). Síndrome do QT Iongo: revisão e relato de caso. Revista da Sociedade de Cardiologia do Rio Grande do Sul, 2: 43-48.

6. Puddu PE, Tubau JF, Krol R, de Champlain J \& Pasternac A (1981). Prolonged QT interval and autonomic imbalance: a clue for the prevention of sudden death in mitral valve prolapse. American Journal of Cardiology, Part 2. (Abstracts of the 30th Annual Scientific Session).
7. Garson Jr A (1993). How to measure the QT interval: what is normal? American Journal of Cardiology, 72: 14B-16B.

8. Benhorin J, Merri M, Alberti M, Locati E, Moss AJ, Hall WJ \& Cui L (1990). Long QT syndrome. New electrocardiographic characteristics. Circulation, 82: 521-527.

9. Zhang L, Timothy KW, Vincent GM et al. (2000). Spectrum of ST-Twave patterns and repolarization parameters in congenital long-QT syndrome: ECG findings identify genotypes. Circulation, 102: 28492855.

10. Das G (1990). OT interval and repolarization time in patients with intraventricular conduction delay. Journal of Electrocardiology, 23: 49-52.

11. Merri M, Benhorin J, Alberti M, Locati E \& Moss AJ (1989). Electrocardiographic quantitation of ventricular repolarization. Circulation, 80: 1301-1308.

12. Fletcher $\mathrm{RH}$, Fletcher SW \& Wagner EH (1996). Clinical Epidemiology: The Essentials. 3rd edn. Williams \& Wilkins, Baltimore, MD, USA.

13. Bland JM \& Altman DG (1999) Measuring agreement in method comparison studies. Statistical Methods in Medical Research, 8: 135-160. 